finger into the rectum a large stone could be felt in the bladder. The patient's health was very bad. He was pale, thin, weak, and anæmic, and he had a pinched, anxious expression, the result of long suffering. On Dec. 5th I performed litholapaxy, the urethral calculus having first been removed after slitting the floor of the urethra slightly. The operation lasted sixty-six minutes, and the débris weighed three ounces and a quarter, the calculus being a hard uric-acid one. Considerable trouble was first experienced in grasping the stone, owing to the contraction of the walls of the bladder on it. This was obviated by injecting water into the bladder. The lithotrite was introduced at least a dozen times, and after each crushing a large quantity of débris was washed out through a No. 18 cannula. With the exception of slight pain in micturition during the first day or two the patient had no after-trouble. He made a rapid recovery, and on Dec. 15th, when discharged from the hospital, the following entry in my note-book describes his condition:- "Patient now rid of all bladder symptoms. Urine quite clear; bladder retains a large quantity at a time. Has grown fat and strong. Says he has not been so well for several years. This man was a miserable creature on admission to hospital ten days ago, and now leaves it in excellent health." This is, as far as I am aware, the largest calculus that has ever been removed from the bladder by the crushing operation at one sitting. The amount of manual labour required in crushing a large and hard stone of this kind is something excessive. I felt completely exhausted after the operation. My hands were blistered from the lithotrite, and the muscles of my arms ached for two or three days subsequently. I cannot too strongly advocate the desirability of removing the whole of the calculus at one sitting. This is the essential principle of the operation. This fact seems to be lost sight of by some surgeons, for I have noticed that in some of their recorded cases a second, and even third, operation was necessary. An operation prolonged over several sittings in this way involves all the dangers of the old operation of lithotrity and ceases to be litholapaxy in my acceptation of the term. Male patients of all ages, from sixteen to ninety-six years, were operated on. The average age was forty-seven years and a half. Several patients of eighty years and over had large calculi removed successfully; and in one case I removed a hard uric-acid stone weighing nine drachms and a half from a patient aged ninety-six, the operation lasting one hour. The details of the case are interesting, so I give them.

CASE 69. - This was a case in private practice. The patient, a Mahomedan of Moradabad, stated that he was close on 100 years of age, and by calculation he appeared to be ninety-six. He was a dried-up, withered creature, without a tooth in his head, and consisting almost of skin and bone only. Several of his sons were living, and one of them looked seventy years of age. Till about a month before coming undsr my treatiment he had enjoyed good health, and used to walk about the bazaar daily. He was suffering from well-marked symptoms of stone, especially great pain in passing urine. He was very weak and unable to leave his bed. On October 28 th, 1883 , I performed litholapaxy, the débris weighing nine drachms and a half, and the operation lasting one hour. The patient made a rapid recovery and was able to walk about on November 13th. Five months afterwards I had the pleasure of showing this old gentleman to Surgeon-General W. Walker. He was then in excellent health, so much so that Dr. Walker writing of him at the time amusingly says: "He must certainly be ninety, and looks as if he might live for thirty years now, and then do service as an old rail."

My experience is that old patients bear the operation much better than young men, and in them it is less likely to be attended by urethral fever. The explanation of this is to be found, I have no doubt, in the fact that the mucous membrane of the bladder and urethra gets less sensitive as life advances, and also that the urethra is more capacious in old than in young men. In several instances very small calculi were removed. The diagnosis of such calculi by the sound is often a matter of extreme difficulty; and experience teaches us that a patient is often sent away from hospital with a stone in his bladder after an opinion to the contrary has been expressed. I cannot speak in terms of too high praise of Sir Henry Thompson's sound. Any sound will detect a large or moderate-sized stone; but when have failed with all other sounds in detecting a smali calculus, Sir Henry Thompson's sound has brought it to light I find from experience, however, that, even with Sir Henry
Thompson's sound, a small calculus lying in some peculiar position in the bladder may evade detection. In the Indian Medical Gazette of March last I called attention to a new method of diagnosis for small calculi by means of the aspirator. The method of employing it is indicated in Case 54 .

(To be concluded.)

\section{TWO CASES OF HYDROCELE IN THE FEMALE.}

\section{BY SAMUEL OSBORN, F.R.C.S. ENG.}

HYDROCELE in the female subject is of sufficient rarity to warrant the following two cases being put on record. Both were admitted as out-patients to the Hospital for Women, Soho-square, within a few weeks of each other, and were sent to me as supposed cases of irreducible hernia. The first case is one of hydrocele of the femoral canal, and of greater rarity than the second, which is one of the canal of Nuck. The first is very similar to a case that was reported in THE LANCET on April 5th, 1879. It is, however, in a younger woman, and both are of especial interest, in showing, equally with hydrocele in the male subject, that if it is desirable to effect a permanent cure, simple tapping is not sufficient. I mean tapping and subsequently allowing the patient to return home, walking or travelling some distance to get there. I am of opinion that if, instead of treating these cases as out-patients, I had simply tapped them manipulated the two sides of the sac by rubbing them together to set up superficial inflammation, and subsequently applied an ice-bag and kept the patients in bed, I should have succeeded in curing them at the first operation, in the same way as I was successful in the case previously reported. The diagnosis of these cases is not easy; the difficulty of examining them by transmitted light is great. An ordinary stethoscope is the best instrument to use for the purpose, but with this care must be taken, as it is very easy to direct the vision against the inner side of the tube and not directly to its opposite end. An absence of impulse on coughing, and sometimes fluctuation, are the diagnostic signs to aid us, but that of transparency by transmitted light is the only trustworthy one.

CASE 1.-Eliza W-, aged thirty, a married woman first noticed a lump in the right thigh seven or eight weeks before she came under observation, which gradually increased in size until it became as large as an ordinary hen's egg. The tumour was exactly in the situation of a femoral hernia, for which she was sent by her medical man. It was soft, with no impulse on coughing; there was indistinct fluctuation, and, although transparent by transmitted light, it was somewhat difficult to obtain this means of diagnosis by reason of its situation. On July 9th the swelling was tapped, and a clear yellow fluid eracuated. A femoral truss was applied to keep up pressure upon the walls of the cyst, after they had been well rubbed together; and the patient returned to her home in Essex, and kept to her bed for a week. Three weeks from the date of the tapping the cyst refilled, and became the same size as at first. On Oct. 10th, the patient being in bed, the cyst was tapped, and, the walls having been thoroughly manipulated, tincture of iodine was injected. This occasioned momentarily great pain, and the cyst was allowed to empty itself of the injected fluid. An ice-bag was applied, and kept on continually for three days. Slight inflammatory swelling took place, but this soon subsided, and she got up after ten days, wearing her femoral truss; the swelling had entirely disappeared. On Dec. 4th there was no return of the swelling, and the use of the truss was discontinued.

CASE 2.- Jane P-_- aged thirty-five, single, had noticed a lump in the right groin for scven years, which had gradually increased in size. She had never worn a truss, but bad used a bandage, which was discontinued on account of its occasioning discomfort. The swelling was the shape and size of a large pear, with the stalk pointing downwards to the labia; it was transparent by transmitted light, with no impulse on coughing, and no alteration in size when lying down or after a night's rest. On Sept. 11th the cyst was tapped and rather more than half a pint of canary-coloured fluid withdrawn. A few movable glands were felt after the evacua- 
tion of the fluid, but the cyst collapsed completely. The walls of the cyst were well manipulated by rubbing the two internal surfaces together. An ice-bag was applied for some four or five hours; and, a right scrotal truss having been applied, she was allowed to return home and ordered to keep her bed for three days. This she did, but immediately she commenced to go about the swelling returned, and became as large as ever. On Nov. 6th the patient was admitted into hospital, and, the cyst having been tapped, about forty minims of Morton's solution were injected. On the 7 th she complained of much pain in the lower part of the abdomen and in the cyst. A considerable quantity of clear fluid came from the puncture during the night, soiling the linen and rendering it quite stiff. By the 9th the swelling had increased in size, being tense and red, although the pain was less. A trocar was inserted and about four ounces of clear claret-coloured fluid were evacuated. On the following day the patient felt much relieved; a considerable quantity of fluid had escaped during the night. On the 18th the cyst was nearly the same size. It was again tapped, and the fluid, which came away with difficulty, necessitated the cyst being well squeezed to thoroughly empty it. A certain portion of the swelling remained, as if partially solidified. About half a drachm of tincture of iodine was then injected, and a flannel spica bandage put on and an ice-bag. The next day the patient felt comfortable, experiencing no pain. On the $22 \mathrm{nd}$ an ice-bag, which had been kept on night and day, was discontinued. Swelling still present, but about half the size it was originally; no fluctuation, and apparently solid; pad and firm pressure applied. On the 27 th the swelling was much less; pressure was still kept up by means of a spica bandage, and a small piece of mercurial ointment was placed on the swelling previous to the bandage. She left the hospital on Dec. 11th, quite cured; no sign of the swelling remained. Maddox-street, $W$.

\section{ACUTE PERFORATING ULCER OF THE ASCENDING COLON.}

BY JAMES OLIVER, M.B. EdIN., M.R.C.P. LOND.

lT has been asserted, and doubtless correctly, that perforating ulcers-leaving out of consideration typhoid, tubercular, and such allies-may, and do, occur throughout the gastro-intestinal canal. The stomach and duodenum are, however, apparently the situations preferred. Few cases are on record where the colon itself has been the seat of perforation. Duodenal ulcer has frequently been noted in connexion with extensive burns of the body; the causation, however, must still remain a mystery. Simple inflammation of the gut rarely gires rise to perforation. Considering how common, comparatively speaking, inflammatory changes in and around the cæcum occur, it is somewhat astonishing that complete ulceration so seldom results. In the case which forms the basis of the few remarks I have to make the ascending colon was the seat of perforation. Two ulcers were discovered side by side longitudinally in the large intestine, two inches and a half above the ileo-creal valve. The larger was about half an inch in diameter, whilst the other was only large enough to admit the tip of a goose-quill. The surrounding tissue was apparently healthy, as well as that intervening between the two openings. Both perforations were round in shape, their margins being perfectly regular. The various coats of the bowel had necrosed to an equal extent throughout; the muscular, however, had retracted, and a partial prolapse, so to speak, of the apparently redundant mucous membrane had resulted. The larger opening from the outside gave the appearance of an artificial anus, whilst the smaller was barely to be detected because of the recoil of the elastic tissue of the gut. The position of the ulcers was as nearly as possible the middle of the posterior surface of the ascending colon. Posteriorly this part of the colon, deriving no covering from the peritoneum, is attached by connective tissue to the fascia corering the quadratus lumborum and the front of the right kidney. Gradually by necrosis, the bowel having become tunnelled, fæcal matter escaped into the areolar tissue, separating by degrees the colon and right kidney from the underlying structures. The peritoneum showed but little sign of inflammatory change, the lower margin of the liver alone betraying any sign of fibrinous exudation, and this but limited. The etiology of perforating ulcer is still a debatable question. It is more than likely, however, that thrombosis is a probable cause, the change resulting being comparable with that occurring under similar circumstances in the brain and spinal cord. Complete occlusion of the smal blood channels brings about a gradual death of the part by staying effectually its nutrition. It is doubtful whether the gastric or intestinal secretions ever aid in its production. Montague-street, w.c.

\section{A NEW SPLTNT FOR THE TREATMENT OF TALIPES.}

Bx F. T. PAUL, F.R.C.S.,

SURGEON TO THE ROYAI SOUTHERN HOSPITAL, IIVERPOOI.

IT has always appeared to me, as a general surgeon, that in our ordinary hospital practice cases of confirmed talipes frequently do not obtain the full amount of benefit that is possible-more frequently, I mean, than other varieties of remediable defects. I suppose that this might be explained, if it be really a fact, in different ways by different surgeons. The explanation that has occurred to me is simply that the mechanical treatment following any operative procedure needs to be so prolonged, and so assiduous during the whole time, that the careful patience of either the surgeon or the

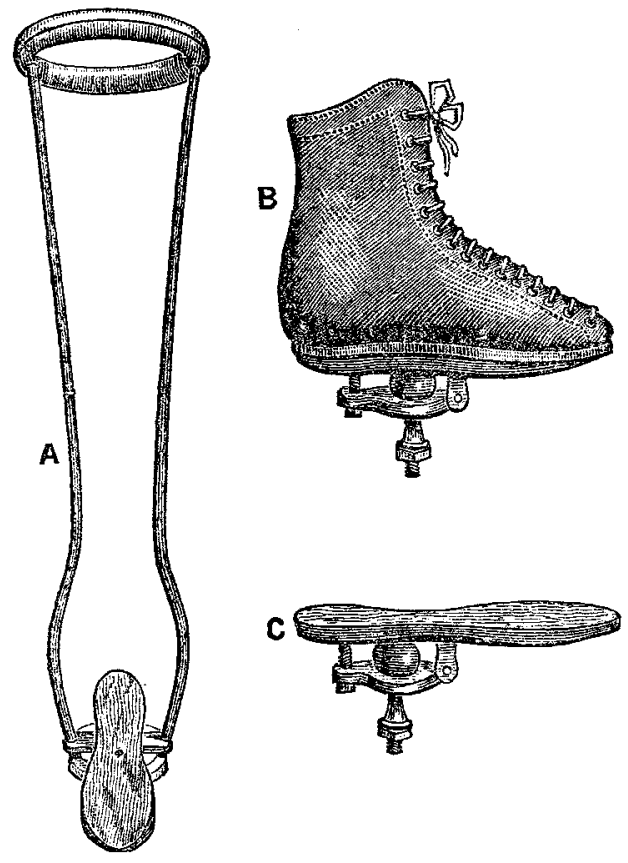

patient often breaks down before the cure has been effectually and permanently established. I have been in the habit of using sheet iron side splints with a foot-piece, fixed on by first firmly strapping the foot to the foot-piece while the foot is in its deformed position, and then forcing the side splint to the leg, and so reducing the deformity. This plan answers well enough if the splint be refixed every few days for six or twelve months. In my own practice I observe that I keep up a pretty close supervision of the case for a month or two, then it gradually drops entirely into the hands of my house-surgeon; subsequently it falls to the care of the nurse, and lastly is lost sight of for a time, and when seen again is often as bad as when it first came under treatment. For a long time I have felt that if a surgeon had the time to undertake a complete supervision of his cases of talipes he could usually cure them by simple mechanical means, and it was owing to the unsatisfactory results that I constantly met with in the practice of my colleagues as well as myself that I attempted to devise a splint which would be so easy to manipulate that the surgeon could himself take in hand the treatment of his talipes cases without that loss of time which at present frequently causes us to relegate the duty to someone else. The splint (see figure) consists of the ordinary side rods and padded ring of a Thomas's knee splint (A). Joining the side rorls at the bottom is a ring to walk upon and a crossbar from one to the other. This latter has a slot in the 